\title{
Assessment of Gait, Balance, and Mobility in Older Adults: Considerations for Clinicians
}

\author{
Addie Middleton • Stacy L. Fritz
}

Published online: 28 August 2013

(C) Springer Science+Business Media New York 2013

\begin{abstract}
Accurate assessment of gait, balance, and mobility in older adults is an important aspect of clinical practice for clinicians working with this population. This report presents evidence regarding assessment in each of these domains. Outcome measures were selected for inclusion if recent evidence (publication within previous 18 months) regarding their properties was available in the literature. Selected measures are as follows: Gait: gait speed, gait symmetry, gait endurance, adaptability of gait, dual task performance during gait, and self-reported confidence during gait; Balance: Berg Balance Scale, Mini-BESTest, Performance-Oriented Mobility Assessment, Dynamic Gait Index, and Falls Efficacy ScaleInternational; Mobility: Timed Up and Go test, 5 times sit-tostand test, backwards walking, and Short Physical Performance Battery. Psychometric properties and minimal detectable change values (when available) for the listed measures are presented in order to provide clinicians with a consolidated reference for selecting outcome measures to assess gait, balance, and mobility in older adults.
\end{abstract}

Keywords Gait · Balance · Mobility · Outcome measures · Reliability $\cdot$ Validity $\cdot$ Minimal detectable change $\cdot$ Older adults $\cdot$ Elderly $\cdot$ Geriatric

\section{Introduction}

The population in the United States is aging [1]. Between 2000 and 2010, the group of persons $\geq 65$ years grew at a faster rate than the total population [1], and this trend is

\author{
A. Middleton $(\triangle) \cdot$ S. L. Fritz \\ Department of Exercise Science, Physical Therapy Program, \\ University of South Carolina, 921 Assembly Street, Columbia, \\ SC 29208, USA \\ e-mail: middletj@email.sc.edu \\ S. L. Fritz \\ e-mail: SFRITZ@mailbox.sc.edu
}

expected to continue [2]. The shift in demographics has public health implications, as the aging process is associated with declines in health [3] and function [4, 5•]. Physical therapists are in a position to address functional impairments in older patients. The role of therapists in the care of this segment of the population includes activities such as evaluating patients, developing plans of care, providing treatment, assessing for orthotic/assistive device needs, and educating patients and caregivers. Being able to accurately assess physical function will improve clinicians' success in the aforementioned tasks. Accurate assessment helps to improve the thoroughness of evaluations, determine appropriate plans of care, better monitor progress, motivate patients, and enhance communication between the therapist and the patient, as well as between the therapist and third party payers [6]. Therefore, determining valid, reliable, and responsive measures for assessing function in older individuals is imperative. Three important domains to consider when assessing functional level are gait, balance, and mobility. The challenge for clinicians is determining accurate measures for quantifying these domains.

In order for clinicians to make an informed decision on the most appropriate outcome measure for their patient and setting, the clinical feasibility, as well as the psychometric properties of the measure, must be taken into account [7]. The psychometric properties to be considered are the validity, reliability, and responsiveness of the outcome measure [8-10]. The authors acknowledge that validity is a broad term and includes aspects such as face validity, content validity, construct validity, concurrent validity, and predictive validity of the measure [11]. For the purposes of this review, the term validity will be used to indicate the extent to which the measure assesses what it is designed to assess. Reliability refers to the reproducibility of a measurement outcome. In order to determine whether or not a patient has truly improved, variability between testing sessions with the same patient (test-retest reliability), between testing sessions performed by the same assessor (intrarater reliability), and between testing sessions performed by different assessors 
(interrater reliability) must be minimized [11]. In addition to being valid and reliable, outcome measures also need to be capable of capturing change when it occurs. Sensitivity and responsiveness are terms used to describe this feature of measures. The sensitivity of a measure refers to its ability to detect change, even if that change is not meaningful. Responsiveness, on the other hand, refers to the ability of a measure to capture "clinically meaningful" change [12]. It is important for clinicians to understand the distinction between sensitivity and responsiveness when referring to the literature on outcome measures. In order to be confident that the change observed in a patient's score on an outcome measure reflects true change, the difference between testing sessions must exceed the measurement error and natural variability that can occur with repeated measurement sessions. The minimal detectable change (MDC) provides clinicians with a reference value to determine if true change has occurred. The $\mathrm{MDC}_{95}$ quantifies the smallest amount of change required to surpass measurement error and variability with a $95 \%$ confidence level. When reported in the literature, MDC scores for outcome measures can be valuable tools for clinicians.

The goal of this review is to provide clinicians with a consolidated reference regarding the assessment of gait, balance, and mobility in older adults. The range of available measures is extensive. In order to narrow it down to a reasonable number for the purposes of this review, the authors selected measures with recently published evidence (i.e., within 18 months of the review). The psychometric properties of the included measures, as well as $\mathrm{MDC}_{95}$ values when available, are reported in the following sections. If standard error of measure (SEM) was provided in the results section of a cited article without the corresponding $\mathrm{MDC}_{95}$, the $\mathrm{MDC}_{95}$ was calculated using the following formula $\mathrm{MDC}_{95}=1.96 * \mathrm{SEM}^{*} \sqrt{2}$ [13]. Table 1 provides a summary of outcome measures included in the article as a quick reference for clinicians. For the purposes of this article, the term "older" is used to refer to individuals $\geq 60$ years of age.

\section{Gait Assessments}

Various parameters of gait can be measured by clinicians during assessment. For example, clinicians can use a patient's gait speed [14, 15], gait symmetry [16], gait endurance [17], adaptability of gait [18], and/or dual-task performance during gait $[19,20 \cdot]$ to quantify gait performance. Evidence on each of these parameters pertaining to older adults is presented below. In addition to these more objective measures, a patient's self-perceptions of gait abilities may also be of interest. Therefore, research findings regarding self-report measures of gait are also included in this section.

\section{Gait Speed}

Research supports the use of gait speed to assess and monitor a patient's current [21] and future [22] functional status; to predict discharge location [23], future hospitalization [24],

Table 1 Summary table of gait, balance, and mobility outcome measures

\begin{tabular}{|c|c|c|c|c|c|}
\hline & Measure & Assessing & Predictive abilities & Scale $^{\mathrm{a}}$ & $\mathrm{MDC}_{95}$ \\
\hline \multirow[t]{5}{*}{ Gait } & 4-Meter Walk Test $[20 \bullet, 21,24,25,33 \bullet \bullet, 35]$ & Gait speed & $\begin{array}{l}\text { Functional status, discharge location, } \\
\text { rehabilitation potential, fall risk, } \\
\text { mortality }\end{array}$ & $\mathrm{n} / \mathrm{a}$ & $0.14 \mathrm{~m} / \mathrm{s}$ \\
\hline & 6-Minute Walk Test $[35,38]$ & Gait endurance & Not established & $\mathrm{n} / \mathrm{a}$ & $58.2 \mathrm{~m}$ \\
\hline & Dynamic Gait Index [39] & $\begin{array}{l}\text { Ability to adapt to changing task } \\
\text { demands during gait }\end{array}$ & Fall risk & $0-24$ & 2.9 points \\
\hline & Walking While Talking Test [48] & $\begin{array}{l}\text { Gait performance under divided } \\
\text { attention conditions }\end{array}$ & Fall risk, frailty, disability, mortality & $\mathrm{n} / \mathrm{a}$ & Not established \\
\hline & Modified Gait Efficacy Scale [49•] & Patients' perceptions of gait abilities & Not established & $10-100$ & 14.7 points \\
\hline \multirow[t]{4}{*}{ Balance } & Berg Balance Scale [51] & Functional balance & Fall risk & $0-56$ & 6.2 points \\
\hline & Mini-BESTest [51] & Dynamic balance control & Not established & $0-28$ & 3.5 points \\
\hline & $\begin{array}{l}\text { Performance-Oriented Mobility } \\
\text { Assessment [59] }\end{array}$ & Balance and gait & Fall risk & $0-28$ & 4.2 points \\
\hline & Falls Efficacy Scale- International [53] & Fear of falling & Not established & $16-64$ & 8 points \\
\hline \multirow[t]{4}{*}{ Mobility } & Timed Up and Go Test [66] & Functional mobility & Fall risk & $\mathrm{n} / \mathrm{a}$ & Not established \\
\hline & 5-Times Sit to Stand Test $[64,70]$ & Mobility and LE strength & $\begin{array}{l}\text { Mobility disability, ADL } \\
\text { and IADL disability }\end{array}$ & $\mathrm{n} / \mathrm{a}$ & Not established \\
\hline & Backward Walking [65] & Mobility & Fall risk & $\mathrm{n} / \mathrm{a}$ & Not established \\
\hline & $\begin{array}{l}\text { Short Physical Performance } \\
\text { Battery }[38,72,73]\end{array}$ & Physical function and mobility & $\begin{array}{l}\text { Mobility disability, } \\
\text { hospitalization, and mortality }\end{array}$ & $0-12$ & 4 points \\
\hline
\end{tabular}

$M D C$ minimal detectable change, $n / a$ not applicable, $L E$ lower extremity, $A D L$ activities of daily living, $I A D L$ instrumental activities of daily living

${ }^{\mathrm{a}}$ Range presented in points 
mortality $[25,26]$, and fall risk $[27,28]$; as well as to determine potential for rehabilitation [29]. Not only is a patient's baseline gait speed important, their gait speed trajectory also has health implications; older individuals with trajectories of decline have a greater risk of mortality than those with more stable trajectories [30]. Therefore, monitoring change in gait speed across time can be a valuable tool for clinicians. Gait speed is a clinically feasible measure, as it is quick, inexpensive, and requires minimal equipment to administer. A variety of testing protocols are available to clinicians; for example, gait speed can be measured for both self-selected and "fast" walking speeds, using a static or dynamic start, and over a variety of distances [31]. Studies involving older adult samples continue to demonstrate the importance of including gait speed as a component of comprehensive assessments [32]. Clinicians may wonder, however, given the multitude of testing protocols, which one demonstrates the soundest psychometric properties? A meta-analysis published in 2012 concluded that both self-selected and "fast" gait speed tests are valid measures that can be used to predict functional decline, hospitalization, and mortality in older adults. Results also indicate that self-selected gait speed is a highly reliable outcome measure. At the time, no studies investigating the reliability of "fast" gait speed that met the criteria for metaanalysis were available [33*•]. A study published after the meta-analysis, however, provides preliminary data regarding the reliability of "fast" gait speed in older patients. This study found 10-meter maximum gait speed tests to be highly reliable in institution-dwelling individuals over the age of 74 years [34]. For clinicians working in environments where space is limited, the 4-Meter Walk Test may be an appropriate alternative to the 10-meter distance. The 4-Meter Walk Test has been shown to be a reliable measure for older adults [35]. However, an important "take home" point for clinicians is that the 4Meter Walk Test and 10-Meter Walk Test do not demonstrate sufficient agreement (concurrent validity), meaning that gait speed values calculated via one method cannot be used interchangeably with gait speed values calculated via the other method [35]. This may be true for other gait speed testing protocols, as well, so caution should be exercised by clinicians when comparing gait speeds if the values were not collected using the same procedure. Results from the study by Peters et al. (2013) also indicate that handheld stopwatches are as reliable as automatic timers [35], which reinforces the concept that gait speed measurements do not require expensive or atypical equipment. An $\mathrm{MDC}_{95}$ value of $0.14 \mathrm{~m} / \mathrm{s}$ has been reported for self-selected gait speed in community-dwelling older adults [36].

\section{Gait Symmetry}

Gait symmetry has been proposed as an adjunctive measure to gait speed to better portray a patient's gait abilities [37]. A study examining gait symmetry in individuals post-stroke and in healthy controls concluded that symmetry is not associated with age [16]. In contrast, gait speed is associated with age. The lack of relationship between gait symmetry and age has clinical implications, as it indicates that impairments in this parameter may be due to disease-related changes in gait rather than age-related changes in gait. Therefore, gait symmetry provides additional information regarding a patient's gait capabilities and may be a useful tool for clinicians during assessment of gait in older patients. Although gait symmetry is an objective, quantifiable parameter, the researchers in the aforementioned study used a GAITRite instrumented walkway to assess symmetry [16], which is not always a clinically feasible option. However, even if unable to quantify gait symmetry due to lack of equipment, observational analysis can be used to describe gait, as well as assess change over time. The modified Gait Abnormality Rating Scale (GARS$\mathrm{M})$ is a seven-item observational measure that demonstrates reliability in older adult patients [38]. The measure does not have to be administered in its entirety. Item 1 on the GARS-M, which assesses gait variability, demonstrates concurrent validity with an instrumented walkway in community-dwelling older adults [39]. If gait variability is of interest, administration of item 1 in isolation provides clinicians with a quick, clinically feasible assessment tool. However, caution should be exercised with use of the GARS-M and all other observational gait analysis measures, as there are limitations. In research studies, participants are often scored based on videoanalysis, which allows for viewing multiple times, viewing in slow motion, and/or pausing of the video as needed [38, 39]. The reliability of observational gait analysis may be decreased without the aid of video recordings [40], but unfortunately, the equipment and time required for video-analysis of gait lacks clinical feasibility. When attempting to score a patient in realtime, clinicians must either analyze several parameters simultaneously or ask the patient to perform multiple trials. In patients with mobility limitations, the performance of multiple trials may not be an option. Limiting observational gait analysis to a few pertinent parameters (e.g., step symmetry/ gait variability) may improve accuracy of assessment and provide clinicians with valuable information.

\section{Gait Endurance}

The Six-Minute Walk Test (6MWT) is a valid and reliable measure of endurance in older adults [41]. Southard et al. (2013) conducted a study to determine how 6MWT distances compared between two different methods of measurement (pedometers versus measuring linear distance) and between two different methods of instruction ("walk as FAR as you can in six minutes" versus "walk as FAST as you can in six minutes" [17]). No differences were found between measurement or instruction methods [17] indicating that either method 
of measurement and/or instruction can be used clinically. Another study investigating administration of the 6MWT revealed statistically significant differences in 6MWT outcomes between 10-meter, 20-meter, and 30-meter walkways, with shorter walkways resulting in decreased distance ambulated during the test [42]. This is likely due to the increased number of turns required with a shorter walkway. The clinical implication of these findings is that in order to draw accurate conclusions from repeated performances of the 6MWT by a patient, the length of the walkway needs to be the same across testing sessions. The change in distance ambulated required to exceed measurement error and variability is 58.2 meters for older adults. This $\mathrm{MDC}_{95}$ was calculated by the authors using the results of a study conducted by Perera et al. (2006) [43].

\section{Adaptability of Gait}

Ambulation does not solely occur in controlled settings free from obstacles/hazards or changes in environment. In order to ascertain a patient's safety in "real world" scenarios, clinicians may need to assess the patient's adaptability of gait. Is the patient able to adapt their gait appropriately in response to changing environmental demands? The Dynamic Gait Index (DGI) is an outcome measure that can be used by clinicians to assess a patient's ability to adapt their gait to changing task demands. Designed originally for use in older adults, the measure includes items such as turning your head vertically and horizontally while walking, performing a $180^{\circ}$ pivot turn during gait in immediate response to a verbal command, stepping over and around obstacles, and ascending and descending a flight of stairs. Scores can range from 0 to 24 points [44]. For older adults, at least a 3-point $\left(\mathrm{MDC}_{95}=2.9\right)$ difference between testing sessions is required in order to be confident that a true change has occurred [44]. Previous studies have established the test's validity [45] and reliability [46, 47] in the older population. However, the instrument demonstrates ceiling effects with higher functioning patients [48, 49•], as well as relatively low sensitivity to change and limited responsiveness [49•]. Research indicates, therefore, that while the DGI is a valid and reliable measure, the ceiling effect and low responsiveness may hinder its ability to capture change in higher functioning older adults.

\section{Dual Task Performance During Gait}

Dual task gait assessments can be administered to help determine fall risk in older adults [50]. By requiring the patient to walk while performing a secondary task, dual task tests assess gait performance under divided attention conditions [51]. Secondary tasks can be classified into the following categories: reaction time tasks, discrimination and decision-making tasks, mental tracking tasks, verbal fluency tasks, and manual tasks [20 ]. Evidence is available to help guide clinicians with selection of type and complexity of secondary tasks. In regards to type of task, performance of discrimination and decision-making tasks (e.g., deciding whether clock hands are on same or different sides of clock face) [52], manual tasks (e.g., carrying cup of water) [53], and mental tracking tasks (e.g., counting backwards by serial subtraction) [53] have all been shown to be associated with fall risk in communitydwelling older adults. Reaction-time tasks $[52,54]$ and verbal fluency tasks $[20 \bullet, 55]$ do not appear to be as informative. A meta-analysis by $\mathrm{Chu}$ et al. (2013) compiled evidence to determine how the complexity of the secondary task performed while walking affected fall risk in older individuals [20•]. The meta-analysis concludes that consideration must be given to the level of complexity; in order for the test to be informative, the degree of difficulty must appropriately challenge the patient. For example, clinicians working with an institutionalized older population may want to include a less complex secondary task, such as counting backwards [20•]. On the other hand, clinicians working with older patients who are higher functioning may want to consider using a more complex secondary task, such as counting backwards by multiples of a number [20 ]. Muhaidat et al. (2013) conducted a study to assess the test-retest reliability of eight dual task and one triple task gait-related tests in a sample of older individuals consisting of fallers and non-fallers [19]. Of the various tests included in the study, the authors found the Walking While Talking (WWT) complex test to be the most reliable. Testing procedure for this assessment involves walking and turning while reciting alternating letters of the alphabet [19]. Previous research supports the reliability and validity of the WWT complex test as a valid and reliable measure for determining fall risk in older individuals [56]. The WWT, although simpler than the WWT complex, has been shown to be a strong predictor of future major health outcomes (frailty, disability, and mortality) [57]. Therefore, the WWT may be an appropriate option for assessing low-functioning older adults, while the WWT complex may be a more informative choice for assessing those functioning at a high level.

\section{Self-Report Measures}

The Gait Efficacy Scale (GES) allows an individual to rate their confidence performing 10 walking tasks. Newell et al. (2012) conducted a study to determine the psychometric properties of a modified version of the GES in older adults [58]. In the modified version (mGES) four of the original tasks (all pertaining to confidence navigating an escalator) were replaced with walking tasks the researchers felt to be more representative of daily mobility. The modified form has patients rate their confidence performing walking tasks such as ambulating over even/uneven surfaces, stepping over an obstacle in their path, stepping up/down a curb, ascending and descending stairs with/without railing, and walking a "long 
distance" (example of 0.5 mile provided on form) [58]. The items are scored on a 10-point scale with higher scores indicating greater confidence. The mGES was found to be a valid and reliable measure of confidence during gait activities in older adults. An $\mathrm{MDC}_{95}$ of 14.7 points was calculated for the measure using the SEM reported in the study conducted by Newell et al. (2012) [58]. The mGES may provide clinicians with a quick, easy to administer gait outcome measure that offers insight into a patient's self-perceptions of their ability to perform gait-related tasks.

\section{Balance Assessments}

Accurate quantification of balance deficits allows clinicians to determine if their patient is at risk of a fall, as well as guide intervention. Evidence demonstrates that clinical measures have the ability to capture balance impairments that signify increased fall risk in community dwelling older patients [59]. A summary of findings from studies examining the following balance assessments are presented in the sections below: Berg Balance Scale (BBS) [49•, 60••, 61], Mini-Balance Evaluation Systems Test (Mini-BESTest) [60••], Performance-Oriented Mobility Assessment (POMA) [49•], and the Falls Efficacy Scale-International (FES-I) [62].

\section{Berg Balance Scale}

The BBS is a valid [63] and reliable [60••] measure of functional balance in older adults. In a study conducted by Pardasaney et al. (2012) [49•], the BBS demonstrated less of a ceiling effect than the POMA or DGI when considering the total sample of older adult subjects. However, a greater ceiling effect for the measure was observed among the higher functioning subgroup of the sample when compared to the lower functioning subgroup [49॰]. A "greater ceiling effect" indicates that more participants in the higher functioning subgroup achieved the maximum possible score on the BBS than in the lower functioning subgroup. Ceiling effects have clinical implications. If a patient scores the maximum possible score on a measure, an uncertainty as to their true capabilities remains [64]. For example, if a patient scores a perfect score on the BBS (56 points), they have "maxed out" that particular measure, but where above the scale the patient's true balance abilities fall is impossible to determine. Also, if a patient achieves the maximum possible score, the measure is no longer informative for monitoring progress over the course of an intervention. A ceiling effect with the BBS has been observed in other studies as well $[60 \bullet \bullet, 65]$. An additional consideration regarding the use of the BBS to assess balance in older adults is the measure's relatively low sensitivity to change and limited responsiveness [49॰]. The $\mathrm{MDC}_{95}$ for the BBS in older adults indicates that a seven-point or greater difference in scores $\left(\mathrm{MDC}_{95}=6.2\right.$ points) is required to be certain a true change in balance has occurred [60*0]. The potential ceiling effect of the BBS, as well as the measures relatively low responsiveness, suggest that clinicians should consider the functional level of their patient when determining the most appropriate balance assessment. With higher functioning individuals it may be beneficial to select a more challenging balance assessment, such as the Mini-BESTest $[60 \bullet \cdot$.

\section{Mini-BESTest}

The relatively lengthy time requirements for administering the BESTest (35-45 minutes) $[60 \bullet \bullet, 66]$ compromises the measure's clinical feasibility. Therefore, a shortened version of the assessment, the Mini-BESTest, was created. Like the BBS, the Mini-BESTest is a 14 item scale. Similar items between the two tests include: transitioning sit to stand, standing on one leg, and standing with feet together. The Mini-BESTest also includes tasks that differentiate it from the BBS, such as assessing a patient's ability to rise onto toes; use compensatory stepping strategies in forward, backward, and lateral directions; stand with feet together and eyes closed on a foam surface; stand with eyes closed on an incline; and perform the following gait tasks: change gait speed, walk with head turns, perform pivot turns, and step over obstacles (items similar to the DGI). The TUG test with and without a mental-tracking dual task (e.g. counting backwards) is also included in the measure [67]. Scores can range from 0 to 28 points, with higher scores indicating better balance function. A study conducted to determine the psychometric properties of the measure concluded that the Mini-BESTest was a valid and reliable test of balance in older adults [60••]. In terms of responsiveness, results from this study indicate that a 4 point difference in score is indicative of a true change in balance (MDC $=3.5$ points). As mentioned previously, the MiniBESTest incorporates more challenging tasks than the BBS $[60 \bullet$. Therefore, the Mini-BESTest may be an appropriate option for assessing balance in relatively high functioning older adults.

\section{Performance-Oriented Mobility Assessment}

A study by Pardasaney et al. (2012) investigated the sensitivity to change and the responsiveness of both the full POMA (comprised of gait and balance subscales) and the balance subscale of the POMA (POMA-B) in older adults [49•]. Both versions of the POMA demonstrated greater ceiling effects than the BBS, as well as relatively low sensitivity to change and limited responsiveness [49•]. For older adults who do not reach the ceiling on the full POMA, a change in score of 5 points is indicative of true change ( $\mathrm{MDC}_{95}$ of 4.2 points) [68]. Combining the information regarding the POMA presented in 
this section with the information regarding the BBS and MiniBESTest presented above, it appears that on a continuum from low-functioning to high-functioning patients, the appropriate balance assessment may be the POMA, BBS, then MiniBESTest, respectively.

\section{Falls Efficacy Scale-International}

The FES is a self-report measure designed to assess an individual's fear of falling during performance of a variety of activities. Six additional items were added to the original FES to create the FES-I. The supplementary items address more difficult activities than those included on the original questionnaire. Other modifications made to create the FES-I include rewording to make all items cross-cultural and adjustment of item scoring from a 10 point scale to a four point scale [69]. The FES-I includes 16 items and scores can range from 16 to 64 points, with higher scores indicating greater confidence. A study conducted by Halvarsson et al. (2013) demonstrated that the FES-I is a reliable measure of fear of falling in older adults [62]. An eight-point or greater change in scores between testing sessions is indicative that a true change in self-perceived balance has occurred [62]. Clinicians may want to consider administering a self-report measure, such as the FES-I, when the patient checks in for therapy as it provides a time-efficient way to gather useful additional information.

\section{Mobility Assessments}

Disability in the mobility domain results in both decreased independence and lower levels of life satisfaction [70]. Since mobility is a common area of intervention for physical therapists, evidence regarding the psychometric properties of outcome measures to assess mobility in older adults (i.e., Timed Up and Go test [71•], 5-time sit to stand test [72, 73], backward walking [74], and short physical performance battery [57]) is presented below. Mobility often includes components of gait and balance, so there is some overlap between tasks performed on these measures and those discussed above. However, mobility measures provide a way to quantify a different aspect of the patient beyond just gait or balance alone. Use of one of the following outcome measures may enhance assessment of older adults.

\section{Timed Up and Go Test}

The Timed Up and Go test (TUG) is designed to assess functional mobility and can be used to predict fall risk in older adults $[75,76]$. The TUG represents a clinically feasible option for assessing mobility as it requires minimal equipment (chair with arms and stop watch), minimal space (3 meters), and minimal time (typically less than five minutes, including instruction delivery). In a prospective study conducted by Alexandre et al. (2012), a time of greater than 12.47 seconds on the TUG was found to be predictive of falls in community-dwelling older adults [75]. This cutoff time is faster than previously published values; for example, Shumway-Cook et al. (2000) reported times greater than 14 seconds as being indicative of high fall risk [76]. A meta-analysis compiling TUG data concluded that the TUG was more useful for determining fall risk in less healthy, lowerfunctioning individuals than in their healthy, higher-functioning peers [ $71 \bullet$. In addition to predicting fall risk, the TUG represents an option for screening for frailty in older adults [77]. Due to the measure's clinical feasibility and predictive capabilities, the TUG may be an appropriate option for assessing mobility in lowerfunctioning older adults.

\section{5-Times Sit to Stand Test}

The 5-times sit-to-stand test (5TSTS) requires patients to stand up from a chair five times as quickly as possible without the use of hand support. The time to complete the task is recorded in seconds, which can then be used to predict future mobility disability $[73,78 \cdot \bullet]$ and disability in activities of daily living (ADL) and instrumental activities of daily living (IADL) in older adults [79]. Regarding outcomes, results indicate that a time to complete of greater than 13.7 seconds is predictive of future mobility disability [73]. The 5TSTS requires minimal equipment (standard height chair and stop watch), minimal space, and minimal time (typically less than 5 minutes, including instruction delivery). Therefore, the 5TSTS may be an appropriate, clinically feasible option for assessing mobility in typical community-dwelling older adults.

\section{Backward Walking}

Backward walking (BW) has been proposed as an additional measurement for assessing mobility in older adults [74]. A study by Fritz et al. (2013) observed BW speed to be a more accurate identifier of fallers than forward walking speed in older individuals [74]. Results from this study suggest that a BW speed of less than $0.6 \mathrm{~m} / \mathrm{s}$ is indicative of fall risk in this population [74]. Although BW speed and spatiotemporal parameters were collected via the GAITRite system in the aforementioned study, which decreases clinical feasibility, we propose that BW speed may be collected using a stop watch and marked distance (e.g., 10 meters). Using this simplified procedure, BW speed may provide clinicians with additional information regarding their patients' mobility.

\section{Short Physical Performance Battery}

The Short Physical Performance Battery (SPPB) is a valid, reliable, and responsive measure of physical function and mobility in community-dwelling older adults [80॰]. The measure is comprised 
of a self-selected walking speed test, a hierarchal balance test (feet side by side, semitandem stance, then tandem stance), and a 5times sit to stand test. Each of the included tests is scored on a $0-4$ scale, making 12 the maximum possible total score. Low scores on the SPPB are predictive of mobility disability [81], hospitalization [82], and mortality [82]. Age- and sex-based normative data is available for the SPPB, which allows clinicians to compare a patient's performance to that of their peers [83]. $\mathrm{An}^{\mathrm{MDC}} \mathrm{MD}_{95}$ of 4 points has been calculated for this population by the authors based on data from a study conducted by Perera et al. (2006) [43]. In addition to the measure's sound psychometric properties and predictive abilities, the SPPB is a clinically feasible option for assessing mobility in older adults as it requires minimal time, space, and equipment.

\section{Additional Mobility Consideration}

Evidence indicates that in geriatric patients, vestibular deficits are associated with mobility impairments [84]. Therefore, clinicians may want to consider assessing vestibular function in patients who display mobility limitations, as this can help guide treatment. The Clinical Test for Sensory Integration in Balancemodified (CTSIB-m) is a clinically feasible option for detecting potential vestibular dysfunction [85]. The measure requires the patient to stand with arms crossed and feet together under four different conditions (standing on the floor with eyes open/eyes closed and standing on a 3" foam cushion with eyes open/eyes closed). Each position is held for 30 seconds; if a patient cannot maintain the position for 30 seconds, time to failure is recorded. Patients are also scored in each position using a 1-4 scale based on postural sway and loss of balance criteria, with lower scores indicating better performance. Difficulty maintaining balance while standing on a foam cushion with eyes closed may be indicative of vestibular deficits [85]. If dysfunction is detected, the patient may benefit from referral to a provider who specializes in vestibular disorders. Intervention strategies addressing vestibular deficits may result in improved mobility outcomes compared to those addressing strength, range of motion, and/or balance without consideration of the vestibular component. Vestibular assessment is often overlooked, but may be especially important when working with older adult patients as the prevalence of vestibular dysfunction in adults is high and increases with age [86]. Clinicians working with older adult patients are in a unique position to screen for vestibular dysfunction and refer patients for appropriate treatment.

\section{Conclusion}

The physical therapy profession is moving in an evidence based practice direction [87], and as a result clinicians are turning to the literature to determine appropriate outcome measures to assess patients. Outcome measures selected should demonstrate sound psychometric properties and responsiveness to change [7, $8,10]$. Searching the literature can be a time consuming task and may be difficult for clinicians with busy schedules. This review article provides clinicians with information regarding outcome measures that can be used to assess gait, balance, and mobility in older adults. However, the scope of information that can be presented in this short article is limited. For this reason, the authors feel it is important to highlight other resources that have been developed to provide clinicians with easily accessible, consolidated information regarding outcome measures. An example is the Rehabilitation Measures Database (rehabmeasures. org), which currently contains information on 194 outcome measures. The information presented is peer-reviewed and comprehensive, and includes: purpose, appropriate populations, time to administer, description, type (observation, questionnaire, etc.), equipment and/or training required, standard error of measure (SEM), MDC, normative data, reliability, validity, floor/ceiling effects, responsiveness, and any additional considerations that should be taken into account by clinicians. Links to the actual instrument (when available) and to abstracts for the articles cited are supplied as well [88]. The Rehabilitation Measures Database and review articles, such as this one, that consolidate research findings provide clinicians with valuable tools for selecting appropriate, evidence based outcome measures.

Acknowledgments The authors wish to thank Denise Peters, PT, DPT for her helpful edits and suggestions during manuscript preparation.

\section{Compliance with Ethics Guidelines}

Conflict of Interest Addie Middleton declares that she has no conflict of interest.

Stacy L. Fritz is supported by grants from the United States Department of Defense and the American Heart Association; has received compensation from Palmetto Health for service as a research consultant; has received honoraria from various clinical groups for lectures, and has been reimbursed for travel/accommodations expenses incurred on speaking engagements.

Human and Animal Rights and Informed Consent This article does not contain any studies with human or animal subjects performed by any of the authors.

\section{References}

Papers of particular interest, published recently, have been highlighted as:

- Of importance

•. Of major importance

1. Werner CA. The older population: 2010. US Census Bureau. 2011. http://www.census.gov/prod/cen2010/briefs/c2010br-09.pdf. Accessed June 27, 2012. 
2. Projected Future Growth of the Older Population. Department of Health \& Human Services, Administration on Aging. 2010. http://www.aoa. gov/AoARoot/Aging Statistics/future growth/future growth.aspx\#age.

3. Diehr PH, Thielke SM, Newman AB, Hirsch C, Tracy R. Decline in health for older adults: five-year change in 13 key measures of standardized health. J Gerontol Ser A, Biol Sci Med Sci. 2013. doi:10.1093/gerona/glt038.

4. Joaquin AM, Gollapudi S. Functional decline in aging and disease: a role for apoptosis. J Am Geriatr Soc. 2001;49(9):1234-40.

5. - Milanovic Z, Pantelic S, Trajkovic N, Sporis G, Kostic R, James N. Age-related decrease in physical activity and functional fitness among elderly men and women. Clin Intervent Aging. 2013;8:54956. doi:10.2147/CIA.S44112. Study including 1288 independent elderly individuals (age 60-80 years). Results indicate that physical activity and functional fitness decline with age. Muscle strength loss appears to be greater in the lower extremities than the upper extremities. The findings suggest that these age-related changes can lead to decreased independence and fall risk, both of which are areas that can be addressed through physical therapy intervention.

6. Jette DU, Halbert J, Iverson C, Miceli E, Shah P. Use of standardized outcome measures in physical therapist practice: perceptions and applications. Phys Ther. 2009;89(2):125-35. doi:10.2522/ptj.20080234.

7. VanSwearingen JM, Brach JS. Making geriatric assessment work: selecting useful measures. Phys Ther. 2001;81(6):1233-52.

8. Guyatt GH, Kirshner B, Jaeschke R. Measuring health status: what are the necessary measurement properties? J Clin Epidemiol. 1992;45(12):1341-5.

9. Mokkink LB, Terwee CB, Patrick DL, Alonso J, Stratford PW, Knol DL, et al. The COSMIN checklist for assessing the methodological quality of studies on measurement properties of health status measurement instruments: an international Delphi study. Qual Life Res. 2010;19(4):539-49. doi:10.1007/s11136-010-9606-8.

10. Riddle D, Stratford P. Is this change real?: Interpreting patient outcomes in physical therapy. 1st ed. F.A. Davis Co.; 2013.

11. O'Sullivan SaS TJ. Physical rehabilitation: assessment and treatment. 4th ed. Philadelphia: F.A. Davis Company; 2001.

12. Liang MH. Longitudinal construct validity: establishment of clinical meaning in patient evaluative instruments. Med Care. 2000;38(9 Suppl):II84-90.

13. Haley SM, Fragala-Pinkham MA. Interpreting change scores of tests and measures used in physical therapy. Phys Ther. 2006;86(5):735-43.

14. Shinkai S, Watanabe S, Kumagai S, Fujiwara Y, Amano H, Yoshida $\mathrm{H}$, et al. Walking speed as a good predictor for the onset of functional dependence in a Japanese rural community population. Age Ageing. 2000;29(5):441-6.

15. Fritz S, Lusardi M. White paper: "walking speed: the sixth vital sign". J Geriatr Phys Ther. 2009;32(2):46-9.

16. Patterson KK, Nadkarni NK, Black SE, McIlroy WE. Gait symmetry and velocity differ in their relationship to age. Gait Posture. 2012;35(4):590-4. doi:10.1016/j.gaitpost.2011.11.030.

17. Southard V, Gallagher R. The 6MWT: will different methods of instruction and measurement affect performance of healthy aging and older adults? J Geriatr Phys Ther. 2013;36(2):68-73. doi:10. 1519/JPT.0b013e318264b5e8.

18. Lindemann U, Klenk J, Becker C, Moe-Nilssen R. Assessment of adaptive walking performance. Med Eng Phys. 2013;35(2):217-20. doi:10.1016/j.medengphy.2012.11.005.

19. Muhaidat J, Kerr A, Evans JJ, Skelton DA. The test-retest reliability of gait-related dual task performance in community-dwelling fallers and non-fallers. Gait Posture. 2013;38(1):43-50. doi:10.1016/j.gaitpost. 2012.10.011.

20. • Chu YH, Tang PF, Peng YC, Chen HY. Meta-analysis of type and complexity of a secondary task during walking on the prediction of elderly falls. Geriatrics Gerontol Int. 2013;13(2):289-97. doi:10. 1111/j.1447-0594.2012.00893.x. Dual task gait assessment may be more beneficial than single task gait assessment for determing fall risk in elderly patients. Fifteen studies were included in this meta-analysis. Results indicate that addition of a simple secondary task (e.g., counting backwards) may be appropriate for instititutionalized elderly patients, while addition of a more complex task (e.g., counting backwards by three's) may be appropriate for community-dwelling elderly patients. Mental tracking dual tasks can be used for fall risk prediction, but further research is needed regarding the addition of manual tasks and verbal fluency tasks.

21. Verghese J, Wang C, Holtzer R. Relationship of clinic-based gait speed measurement to limitations in community-based activities in older adults. Arch Phys Med Rehabil. 2011;92(5):844-6. doi:10. 1016/j.apmr.2010.12.030.

22. Purser JL, Weinberger M, Cohen HJ, Pieper CF, Morey MC, Li T, et al. Walking speed predicts health status and hospital costs for frail elderly male veterans. J Rehabil Res Dev. 2005;42(4):535-46.

23. Rabadi MH, Blau A. Admission ambulation velocity predicts length of stay and discharge disposition following stroke in an acute rehabilitation hospital. Neurorehabil Neural Repair. 2005;19(1):20-6. doi: $10.1177 / 1545968304272762$.

24. Montero-Odasso M, Schapira M, Soriano ER, Varela M, Kaplan R, Camera LA, et al. Gait velocity as a single predictor of adverse events in healthy seniors aged 75 years and older. J Gerontol Ser A, Biol Sci Med Sci. 2005;60(10):1304-9.

25. Hardy SE, Perera S, Roumani YF, Chandler JM, Studenski SA. Improvement in usual gait speed predicts better survival in older adults. J Am Geriatr Soc. 2007;55(11):1727-34. doi:10.1111/j. 1532-5415.2007.01413.x.

26. Studenski S, Perera S, Patel K, Rosano C, Faulkner K, Inzitari M, et al. Gait speed and survival in older adults. JAMA. 2011;305(1):50 8. doi:10.1001/jama.2010.1923.

27. Quach L, Galica AM, Jones RN, Procter-Gray E, Manor B, Hannan MT, et al. The nonlinear relationship between gait speed and falls: the maintenance of balance, independent living, intellect, and zest in the elderly of boston study. J Am Geriatr Soc. 2011;59(6):1069-73. doi:10.1111/j.1532-5415.2011.03408.x.

28. Abellan van Kan G, Rolland Y, Andrieu S, Bauer J, Beauchet O, Bonnefoy M, et al. Gait speed at usual pace as a predictor of adverse outcomes in community-dwelling older people an International Academy on Nutrition and Aging (IANA) Task Force. J Nutr, Health Aging. 2009;13(10):881-9.

29. Goldie PA, Matyas TA, Evans OM. Deficit and change in gait velocity during rehabilitation after stroke. Arch Phys Med Rehabil. 1996;77(10):1074-82.

30. White DK, Neogi T, Nevitt MC, Peloquin CE, Zhu Y, Boudreau RM, et al. Trajectories of gait speed predict mortality in well-functioning older adults: the health, aging and body composition study. J Gerontol Ser A, Biol Sci Med Sci. 2013;68(4):456-64. doi:10.1093/gerona/gls197.

31. Fritz SL, Peters DM, Greene JV. Measuring walking speed. Topics Geriatr Rehabil. 2011;28(2):1-6.

32. Peel NM, Kuys SS, Klein K. Gait speed as a measure in geriatric assessment in clinical settings: a systematic review. J Gerontol Ser A, Biol Sci Med Sci. 2013;68(1):39-46. doi:10.1093/gerona/gls174.

33. •• Rydwik E, Bergland A, Forsen L, Frandin K. Investigation into the reliability and validity of the measurement of elderly people's clinical walking speed: a systematic review. Physiother Theory Pract. 2012;28(3):238-56. doi:10.3109/09593985.2011.601804. Gait speed is an important assessment tool for physical therapists working with elderly patients due to its abilities to determine functional status and predict a variety of future adverse outcomes. Compiling the results of 86 studies, this article concludes that both self-selected and maximal gait speed tests are valid measures in this population. In terms of reliability, self-selected gait speeds were found to be reliable, whereas maximal walking speed tests require further investigation.

34. Adell E, Wehmhorner S, Rydwik E. The test-retest reliability of 10 meters maximal walking speed in older people living in a residential care unit. $\mathrm{J}$ Geriatr Phys Ther. 2013;36(2):74-7. doi:10.1519/JPT.0b013e318264b8ed. 
35. Peters DM, Fritz SL, Krotish DE. Assessing the reliability and validity of a shorter walk test compared with the 10-meter walk test for measurements of gait speed in healthy, older adults. J Geriatr Phys Ther. 2013;36(1):24-30. doi:10.1519/JPT.0b013e318248e20d.

36. Goldberg A, Schepens S. Measurement error and minimum detectable change in 4-meter gait speed in older adults. Aging Clin Exp Res. 2011;23(5-6):406-12.

37. Patterson KK, Gage WH, Brooks D, Black SE, Mcllroy WE. Changes in gait symmetry and velocity after stroke: a cross-sectional study from weeks to years after stroke. Neurorehabil Neural Repair. 2010;24(9):783-90. doi:10.1177/1545968310372091.

38. VanSwearingen JM, Paschal KA, Bonino P, Yang JF. The modified gait abnormality rating scale for recognizing the risk of recurrent falls in community-dwelling elderly adults. Phys Ther. 1996;76(9):994-1002.

39. Huang WN, VanSwearingen JM, Brach JS. Gait variability in older adults: observational rating validated by comparison with a computerized walkway gold standard. Phys Ther. 2008;88(10):1146-53. doi:10.2522/ptj.20070243.

40. Coutts F. Gait analysis in the therapeutic environment. Manual Ther. 1999;4(1):2-10.

41. Steffen TM, Hacker TA, Mollinger L. Age- and gender-related test performance in community-dwelling elderly people: Six-minute walk test, Berg Balance Scale, timed up \& go test, and gait speeds. Phys Ther. 2002;82(2):128-37.

42. Ng SS, Yu PC, To FP, Chung JS, Cheung TH. Effect of walkway length and turning direction on the distance covered in the 6minute walk test among adults over 50 years of age: a crosssectional study. Physiotherapy. 2013;99(1):63-70. doi:10.1016/j. physio.2011.11.005.

43. Perera S, Mody SH, Woodman RC, Studenski SA. Meaningful change and responsiveness in common physical performance measures in older adults. J Am Geriatr Soc. 2006;54(5):743-9. doi:10. 1111/j.1532-5415.2006.00701.x.

44. Romero S, Bishop MD, Velozo CA, Light K. Minimum detectable change of the Berg Balance Scale and dynamic gait index in older persons at risk for falling. J Geriatr Phys Ther. 2011;34(3):131-7. doi:10.1519/JPT.0b013e3182048006.

45. Shumway-Cook A, Baldwin M, Polissar NL, Gruber W. Predicting the probability for falls in community-dwelling older adults. Phys Ther. 1997;77(8):812-9.

46. Jonsson LR, Kristensen MT, Tibaek S, Andersen CW, Juhl C. Intra- and interrater reliability and agreement of the Danish version of the dynamic gait index in older people with balance impairments. Arch Phys Med Rehabil. 2011;92(10):1630-5. doi:10.1016/j.apmr.2011.04.020.

47. Shumway-Cook A, Gruber W, Baldwin M, Liao S. The effect of multidimensional exercises on balance, mobility, and fall risk in community-dwelling older adults. Phys Ther. 1997;77(1):46-57.

48. Dye DC, Eakman AM, Bolton KM. Assessing the validity of the dynamic gait index in a balance disorders clinic: an application of rasch analysis. Phys Ther. 2013;93(6):809-18. doi:10.2522/ptj. 20120163.

49. • Pardasaney PK, Latham NK, Jette AM, Wagenaar RC, Ni P, Slavin $\mathrm{MD}$, et al. Sensitivity to change and responsiveness of four balance measures for community-dwelling older adults. Phys Ther. 2012;92(3):388-97. doi:10.2522/ptj.20100398. Retrospective study including data from 111 community-dwelling elderly individuals. The Berg Balance Scale, Performance-Oriented Mobility Assessment (total test and balance subscale), and the Dynamic Gait Index all demonstrated ceiling effects, low sensitivity to change, and limited responsiveness, most notably in the higher-functioning subsample. These measures may be inappropriate for higher-functioning elderly patients. A more challenging balance assessment may need to be selected for these individuals.

50. Zijlstra A, Ufkes T, Skelton DA, Lundin-Olsson L, Zijlstra W. Do dual tasks have an added value over single tasks for balance assessment in fall prevention programs? A mini-review. Gerontology. 2008;54(1):40-9. doi:10.1159/000117808.
51. Alexander NB, Hausdorff JM. Guest editorial: linking thinking, walking, and falling. J Gerontol Ser A, Biol Sci Med Sci. 2008;63(12):1325-8.

52. Faulkner KA, Redfern MS, Cauley JA, Landsittel DP, Studenski SA, Rosano C, et al. Multitasking: association between poorer performance and a history of recurrent falls. J Am Geriatr Soc. 2007;55(4):570-6. doi:10.1111/j.1532-5415.2007.01147.x.

53. Nordin E, Moe-Nilssen R, Ramnemark A, Lundin-Olsson L. Changes in step-width during dual-task walking predicts falls. Gait Posture. 2010;32(1):92-7. doi:10.1016/j.gaitpost.2010.03.012.

54. Al-Yahya E, Dawes H, Smith L, Dennis A, Howells K, Cockburn J. Cognitive motor interference while walking: a systematic review and meta-analysis. Neurosci Biobehav Rev. 2011;35(3):715-28. doi:10. 1016/j.neubiorev.2010.08.008.

55. Baetens T, De Kegel A, Palmans T, Oostra K, Vanderstraeten G, Cambier D. Gait analysis with cognitive-motor dual tasks to distinguish fallers from nonfallers among rehabilitating stroke patients. Arch Phys Med Rehabil. 2013;94(4):680-6. doi:10.1016/j.apmr.2012.11.023.

56. Verghese J, Buschke H, Viola L, Katz M, Hall C, Kuslansky G, et al. Validity of divided attention tasks in predicting falls in older individuals: a preliminary study. J Am Geriatr Soc. 2002;50(9):1572-6.

57. Verghese J, Holtzer R, Lipton RB, Wang C. Mobility stress test approach to predicting frailty, disability, and mortality in high-functioning older adults. J Am Geriat Soc. 2012;60(10):1901-5. doi:10.1111/j.1532-5415. 2012.04145.x

58. Newell AM, VanSwearingen JM, Hile E, Brach JS. The modified gait efficacy scale: establishing the psychometric properties in older adults. Phys Ther. 2012;92(2):318-28. doi:10.2522/ptj.20110053.

59. Muir SW, Berg K, Chesworth B, Klar N, Speechley M. Quantifying the magnitude of risk for balance impairment on falls in communitydwelling older adults: a systematic review and meta-analysis. J Clin Epidemiol. 2010;63(4):389-406. doi:10.1016/j.jclinepi.2009.06.010.

60. •• Godi M, Franchignoni F, Caligari M, Giordano A, Turcato AM, Nardone A. Comparison of reliability, validity, and responsiveness of the mini-BESTest and Berg Balance Scale in patients with balance disorders. Phys Ther. 2013;93(2):158-67. doi:10.2522/ptj.20120171. Prospective study including 93 elderly patients investigating a condensed version of the BESTest. The Mini-BESTest was found to have less of a ceiling effect and higher reliability than the Berg Balance Scale. Results indicate that the Mini-BESTest may be an appropriate option for assessing balance in higher-functioning elderly patients.

61. Pereira VV, Maia RA, Silva SM. The functional assessment Berg Balance Scale is better capable of estimating fall risk in the elderly than the posturographic balance stability system. Arq Neuropsiquiatr. 2013;71(1):5-10.

62. Halvarsson A, Franzen E, Stahle A. Assessing the relative and absolute reliability of the falls efficacy scale-international questionnaire in elderly individuals with increased fall risk and the questionnaire's convergent validity in elderly women with osteoporosis. Osteoporos Int. 2013;24(6):1853-8. doi:10.1007/s00198-012-2197-1.

63. Berg KO, Wood-Dauphinee SL, Williams JI, Maki B. Measuring balance in the elderly: validation of an instrument. Can J Public Health. 1992;83 Suppl 2:S7-S11.

64. Wang L, Zhang Z, McArdle JJ, Salthouse TA. Investigating ceiling effects in longitudinal data analysis. Multivar Behav Res. 2009;43(3):476-96. doi:10.1080/00273170802285941.

65. Santos GM, Souza AC, Virtuoso JF, Tavares GM, Mazo GZ. Predictive values at risk of falling in physically active and no active elderly with Berg Balance Scale. Rev Bras Fisioterapia. 2011;15(2):95-101.

66. Franchignoni F, Horak F, Godi M, Nardone A, Giordano A. Using psychometric techniques to improve the balance evaluation systems test: the mini-BESTest. J Rehabil Med. 2010;42(4):323-31. doi:10. 2340/16501977-0537.

67. King L, Horak F. On the mini-BESTest: scoring and the reporting of total scores. Phys Ther. 2013;93(4):571-5. doi:10.2522/ptj.2013.93.4.571. 
68. Faber MJ, Bosscher RJ, van Wieringen PC. Clinimetric properties of the performance-oriented mobility assessment. Phys Ther. 2006;86(7):944-54.

69. Yardley L, Beyer N, Hauer K, Kempen G, Piot-Ziegler C, Todd C. Development and initial validation of the Falls Efficacy ScaleInternational (FES-I). Age Ageing. 2005;34(6):614-9. doi:10.1093/ ageing/afi196.

70. Mollaoglu M, Tuncay FO, Fertelli TK. Mobility disability and life satisfaction in elderly people. Arch Gerontol Geriatr. 2010;51(3):e115-9. doi:10.1016/j.archger.2010.02.013.

71. - Schoene D, Wu SM, Mikolaizak AS, Menant JC, Smith ST, Delbaere K, et al. Discriminative ability and predictive validity of the timed up and go test in identifying older people who fall: systematic review and meta-analysis. J Am Geriatr Soc. 2013;61(2):202-8. doi:10.1111/jgs.12106. Results were compiled from 53 studies. The authors conclude that the timed up and go test is a more accurate predictor of fall risk in less healthy, lower-functioning elderly individuals than it is in higher-functioning elderly individuals.

72. Jordre B, Schweinle W, Beacom K, Graphenteen V, Ladwig A. The five times sit to stand test in senior athletes. J Geriatr Phys Ther. 2013;36(1):47-50. doi:10.1519/JPT.0b013e31826317b5.

73. Deshpande N, Metter EJ, Guralnik J, Bandinelli S, Ferrucci L. Predicting 3-year incident mobility disability in middle-aged and older adults using physical performance tests. Arch Phys Med Rehabil. 2013;94(5):994-7. doi:10.1016/j.apmr.2012.10.032.

74. Fritz NE, Worstell AM, Kloos AD, Siles AB, White SE, Kegelmeyer DA. Backward walking measures are sensitive to age-related changes in mobility and balance. Gait Posture. 2013;37(4):593-7. doi:10. 1016/j.gaitpost.2012.09.022.

75. Alexandre TS, Meira DM, Rico NC, Mizuta SK. Accuracy of timed up and go test for screening risk of falls among community-dwelling elderly. Rev Bras Fisioterapia. 2012;16(5):381-8.

76. Shumway-Cook A, Brauer S, Woollacott M. Predicting the probability for falls in community-dwelling older adults using the timed up \& go test. Phys Ther. 2000;80(9):896-903.

77. Savva GM, Donoghue OA, Horgan F, O'Regan C, Cronin H, Kenny RA. Using timed up-and-go to identify frail members of the older population. J Gerontol Ser A, Biol Sci Med Sci. 2013;68(4):441-6. doi:10.1093/gerona/gls190.

78. •• Wang CY, Yeh CJ, Hu MH. Mobility-related performance tests to predict mobility disability at 2-year follow-up in community-dwelling older adults. Arch Gerontol Geriatr. 2011;52(1):1-4. doi:10.1016/j. archger.2009.11.001. Analyzed data from 102 community-dwelling elderly individuals to determine predictive abilities of the following measures: functional reach, timed chair stands (5 times sit to stand test), timed up and go, grip strength, self-selected and maximal gait speed, and six minute walk test. The 5 times sit to stand test was the only measure found to predict mobility disability in this sample at a 2 year follow up.
79. Zhang F, Ferrucci L, Culham E, Metter EJ, Guralnik J, Deshpande N. Performance on five times sit-to-stand task as a predictor of subsequent falls and disability in older persons. J Aging Health. 2013;25(3):478-92. doi:10.1177/0898264313475813.

80. - Freiberger E, de Vreede P, Schoene D, Rydwik E, Mueller V, Frandin K, et al. Performance-based physical function in older community-dwelling persons: a systematic review of instruments. Age Ageing. 2012;41(6):712-21. doi:10.1093/ageing/afs099. Using data from 78 articles, the authors investigated the reliabilty of 12 and validity of nine measures designed to assess functional status of community-dwelling elderly individuals. The Short Physical Performance Battery demonstrated the highest validity, reliability, and responsiveness of the included measures, indicating this may be the best choice for clinicians.

81. Guralnik JM, Ferrucci L, Pieper CF, Leveille SG, Markides KS, Ostir $\mathrm{GV}$, et al. Lower extremity function and subsequent disability: consistency across studies, predictive models, and value of gait speed alone compared with the short physical performance battery. J Gerontol Ser A, Biol Sci Med Sci. 2000;55(4):M221-31.

82. Penninx BW, Ferrucci L, Leveille SG, Rantanen T, Pahor M, Guralnik JM. Lower extremity performance in nondisabled older persons as a predictor of subsequent hospitalization. J Gerontol Ser A, Biol Sci Med Sci. 2000;55(11):M691-7.

83. Guralnik JM, Simonsick EM, Ferrucci L, Glynn RJ, Berkman LF, Blazer DG, et al. A short physical performance battery assessing lower extremity function: association with self-reported disability and prediction of mortality and nursing home admission. J Gerontol. 1994;49(2):M85-94.

84. Golder MD, Earl EM, Mallery LH. Vestibular and motor contributions to mobility: limitations of seniors awaiting discharge from hospital care. Physiother Res Int. 2012;17(4):200-7. doi:10.1002/ pri.532.

85. Maranhao-Filho PA, Maranhao ET, Silva MM, Lima MA. Rethinking the neurological examination I: static balance assessment. Arquivos Neuro-psiquiatria. 2011;69(6):954-8.

86. Agrawal Y, Carey JP, Della Santina CC, Schubert MC, Minor LB. Disorders of balance and vestibular function in US adults: data from the National Health and Nutrition Examination Survey, 2001-2004. Arch Int Med. 2009;169(10):938-44. doi:10.1001/archinternmed. 2009.66.

87. APTA Vision Sentence for Physical Therapy 2020 and APTA Vision Statement for Physical Therapy 2020. American Physical Therapy Association. 2012. http://www.apta.org/uploadedFiles/APTAorg/ About_Us/Policies/Goals_Missions/VisionSentenceStatement.pdf\# search $=022$ vision.

88. Rehabilitation Measures Database. Rehabilitation Institute of Chicago. 2013. http://www.rehabmeasures.org. 